JURNAL MAKSIPRENEUR, Vol. VI, No. 2, Juni 2017, hal. 56 - 65

\title{
ANALISIS REAKSI PASAR MODAL ATAS PENGUMUMAN KENAIKAN BI RATE TANGGAL 12 NOVEMBER 2013
}

\author{
Dwi Cahyaningdyah \\ Nidya Arum Cahyasani \\ Fakultas Ekonomi Universitas Negeri Semarang \\ Korespondensipenulis: dcahyaningdyah@yahoo.com
}

\begin{abstract}
The purpose of this study was to analyze differences in the market reaction, as measured by abnormal returns and trading volume activity in the period before and after the announcement of the increase in the BI Rate. This study uses event study research design, observation period were 10 days before and 10 days after the event. The populations in this study were all members of LQ45 companies. The study sample was taken by purposive sampling technique. The method of data collection is the documentation. The variables of this study are the abnormal return and trading volume activity. The analysis used in this study is different test paired sample t-test. Based on the research results, the stock market reaction test showed no significant difference between the average abnormal return before and after the announcement of the increase in the BI Rate. While testing the reaction by using the average trading volume activity indicators showed a significant difference between the periods before and after the announcement of the increase in the BI Rate.
\end{abstract}

Keywords: event study, abnormal return, trading volume activity, BI Rate

\section{PENDAHULUAN}

Pasar modal pada prinsipnya merupakan sarana bertemunya pihak yang memerlukan modal dengan pemilik modal, baik perorangan maupun kelompok dengan berbagai jenis sekuritas yang menawarkan tingkat keuntungan atau return dengan risiko yang berbeda. Di samping itu, pasar modal juga mendorong terciptanya alokasi dana yang efisien, karena dengan adanya pasar modal maka pihak yang kelebihan dana (investor) dapat memilih alternatif investasi yang memberikan return yang paling optimal (Tandelilin, 2010: 26).

Investor memiliki berbagai pilihan jenis sekuritas untuk berinvestasi selain pada saham. Alasan pemilihan saham untuk berinvestasi oleh investor adalah agar memperoleh return yang lebih besar dibanding berinvestasi di tempat lainnya seperti meletakkan dana pada sektor perbankan. Informasi baru pada pasar modal akan mempengaruhi harga saham perusahaan dan lebih lanjut akan mempengaruhi pengambilan keputusan oleh investor (Linawati, 2009: 1). Informasi dapat digunakan investor untuk menentukan langkah-langkah investasi yang tepat sehingga, pemanfaatan informasi sebagai dasar atas alokasi investasi dapat optimal. Agar pengambilan keputusan investor rasional, dibutuhkan suatu informasi yang relevan sehingga mampu 
mengidentifikasi kinerja perusahaan. Dengan kata lain, keputusan investasi yang dilakukan oleh investor merupakan reaksi atas informasi yang mereka terima (Rokhman dkk, 2009: 2).

Informasi merupakan kebutuhan utama bagi investor, karena informasi tersebut digunakan investor untuk mengambil keputusan investasi. Tingkat kecepatan pasar modal dalam merespon atau menyerap informasi baru merupakan salah satu indikator tingkat efisien. Pasar modal dikatakan efisien apabila dapat mewujudkan suatu kondisi dimana harga-harga saham mampu mencerminkan seluruh informasi yang tersedia. Berdasarkan konsep pasar efisien pergerakan harga sekuritas emiten sangat bergantung pada faktor informasi, informasi tersebut dapat berupa informasi masa lalu, informasi yang dipublikasikan maupun informasi private. Adanya informasi baru pada pasar modal akan mempengaruhi harga saham perusahaan dan lebih lanjut akan mempengaruhi pengambilan keputusan oleh para investor. Informasi sendiri dibagi menjadi dua yaitu informasi internal dan informasi eksternal (Fama, 1997: 284).

BI rate merupakan suatu tingkat suku bunga yang dikeluarkan oleh Bank sentral (Bank Indonesia) sebagai indikator tingkat risiko. Dalam website resmi Bank Indonesia dijelaskan bahwa BI Rate sebagai suku bunga acuan adalah suku bunga kebijakan yang mencerminkan sikap atau stance kebijakan moneter yang ditetapkan oleh bank Indonesia dan diumumkan kepada publik. Di Bursa Efek Indonesia (BEI), kebijakan pemerintah seperti tingkat suku bunga ikut memberikan pengaruh terhadap transaksi yang terjadi di lantai bursa. Kenaikan BI Rate sangat berpengaruh terhadap penyesuaian tingkat bunga dasar kredit. Hal ini kemungkinan disebabkan kenaikan biaya bunga seiring dengan kenaikan BI Rate yang mengakibatkan penurunan kemampuan membayar debitur (Kajian Stabilitas Keuangan No. 8 Maret 2007-BI). Pengumuman pemerintah tentang tingkat suku bunga akan mempengaruhi pengeluaran perusahaan untuk membayar hutangnya. Semakin tinggi tingkat suku bunga maka akan semakin tinggi pula perusahaan harus mengalokasikan dananya untuk membayar bunga dari hutangnya. Berdasarkan pengumuman Bank Indonesia tertanggal 12 November 2013, untuk mempertahankan laju inflasi dan mempertimbangkan kondisi ekonomi global, Bank Indonesia menetapakan suku bunga di angka 7.5\%.

BI rate sebesar $7.5 \%$ yang diumumkan pada tanggal 12 November 2013 merupakan BI rate tertinggi dibandingkan bulan-bulan sebelumnya. Tahun 2013 merupakan tahun dengan ekspektasi inflasi tahunan dengan prediksi tertinggi sebesar 9,8 persen dan kenaikan BI Rate sebesar 25 basis poin ini bertujuan untuk menekan defisit dan menyehatkan transaksi berjalan dalam jangka panjang agar nilai tukar rupiah akan stabil ke depannya untuk menghindari gejolak nilai tukar yang semakin tajam. Dengan dikeluarkannya pengumuman tersebut pasar menanggapi informasi tersebut setelah tanggal tanggal 12 November 2013 indeks LQ45 mengalami penurunan dibanding hari-hari sebelumnya. Hal ini berarti bahwa pasar menanggapi secara negatif pengumuman kenaikan BI rate tanggal 12 November 2013 yang mencapai titik tertinggi selama tahun 2013.

Perubahan kebijakan suku bunga acuan yang dilakukan oleh bank sentral tidak hanya terjadi di Indonesia, di Amerika The Federal Reserve Bank (FED) juga melakukan koreksi atas suku bunga acuan untuk menjaga stabilitas ekonomi Amerika. Beberapa penelitian juga dilakukan menghasilkan hasil penelitian yang berbeda seperti penelitian yang dilakukan Bernanke \& Kuttner (2005: 1253) menjelaskan pengurangan 25 basis poin tingkat bunga The FED menyebabkan kenaikan pada harga saham index sebesar $1 \%$ yang berarti pasar modal merespon adanya informasi baru. Namun pada 
penelitian yang dilakukan Birru \& Figlewski (2010: 26) adanya pengumuman tingkat suku bunga acuan yang baru tidak direspon pasar modal dibuktikan tidak ada perubahan sebelum dan setelah pengumuman yang dilihat dari return.

Penelitian yang dilakukan di Indonesia juga terdapat ketidakkonsistenan hasil penelitian mengenai pasar efisien dalam bentuk setengah kuat dengan melihat dampak dari suatu pengaruh pengumuman kondisi makro ekonomi yang menunjukkan beberapa perbedaan. Penelitian oleh Lantara (2004:10) mengenai perubahan suku bunga dan kinerja pasar modal Indonesia menunjukkan penurunan suku bunga berdampak reaksi positif terhadap return pasar dan kenaikan suku bunga menimbulkan reaksi negatif terhadap return pasar. Penelitian Lantara (2004:11) menyimpulkan bahwa pasar bereaksi terhadap pengumuman perubahan suku bunga. Penelitian lain yang menyatakan bahwa suku bunga mampu mempengaruhi pasar adalah penelitian Tjahjono (2004: 9) yang menyatakan bahwa suku bunga berpengaruh negatif terhadap indeks saham LQ45. Hal yang sama terdapat pada penelitian Linawati (2009: 65) mengenai dampak pengumuman kenaikan BI Rate di respon oleh pasar dengan ditunjukan adanya perbedaan rata- rata trading volume activity sebelum dan setelah pengumuman namun respon pasar tersebut tidak ditunjukkan dengan adanya abnormal return sebelum dan setelah pengumuman kenaikan BI Rate.

Hasil yang berbeda didapatkan pada penelitian oleh Iswardono (1999: 9). menyatakan bahwa suku bunga yang diturunkan tidak menjadikan investasi meningkat. Penelitian Ulumuddin (2010: 87) mengenai dampak pengumuman penurunan BI Rate oleh Bank Indonesia juga menunjukkan bahwa pasar menganggap pengumuman tersebut sebagai "no news" karena tidak terdapat return realisasi yang signifikan pada hari sebelum dan setelah pengumuman tersebut, yang berarti juga pasar tidak bereaksi terhadap pengumuman tentang penurunan tingkat suku bunga acuan. Uraian yang telah dikemukakan tersebut, mendorong peneliti untuk mengetahui bagaimana dampak pengumuman kenaikan BI Rate tanggal 12 November 2013 terhadap beberapa indikator yang dijadikan variabel dan biasa digunakan untuk melihat reaksi pasar. Dalam peneitian ini reaksi tercermin dari tingkat keuntungan yang diukur dengan variabel abnormal return serta tingkat likuiditas saham yang dikur dengan aktivitas volume perdagangan atau Trading Volume Activity (TVA).

\section{Kerangka Pemikiran Teoritis}

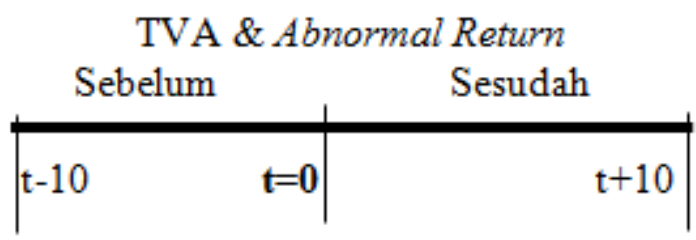

Gambar 1. Periode Pengamatan dan Event Window pada Peristiwa Pengumuman Kenaikan BI Rate

Berdasarkan kerangka berfikir pada Gambar 1 terlihat bahwa hari 0 merupakan hari terjadinya pengumuman peristiwa. Dua puluh satu (21) hari periode jendela (event window) yang diambilkan mulai dari sepuluh hari sebelum tanggal peristiwa (hari -10 ) sampai sepuluh hari setelah tanggal peristiwa $($ hari +10$)$ juga dapat dikatakan, sepuluh hari disekitar peristiwa (yaitu sepuluh hari sebelum, hari peristiwanya, dan sepuluh hari 
sesudahnya). Event window ini digunakan sebagai periode pengamatan reaksi pasar modal, pada periode sebelum pengumuman kenaikan BI Rate $(\mathrm{t}=0)$ apakah terjadi kebocoran informasi, yaitu apakah pasar sudah mendengar informasinya sebelum kebijakan kenaikan BI Rate diumumkan dan periode sesudah pengumuman untuk mengetahui kecepatan reaksi pasar yang terjadi akibat pengumuman kenaikan BI Rate.

\section{METODE PENELITIAN}

Penelitian ini merupakan jenis penelitian kuantitatif, dan menggunakan desain penelitian event study dengan menggunakan pengumuman kenaikan BI Rate sebagai peristiwa, dengan periode pengamatan 10 hari sebelum dan 10 hari setelah peristiwa. Populasi yang digunakan pada penelitian ini adalah semua perusahaan yang terdaftar di Bursa Efek Indonesia (BEI) sebagai anggota Indeks LQ45 periode bulan Agustus 2013 sampai Januari 2014. Teknik pengambilan sampel pada penelitian ini adalah dengan metode purposive sampling. Menurut Ferdinand (2011: 223), purposive sampling ialah jenis pemilihan sampel dengan menggunakan beberapa kriteria atau pertimbangan tertentu yang disesuaikan dengan tujuan penelitian atau masalah penelitian yang dikembangkan.

Penentuan sampel dilakukan berdasarkan metode purposive sampling yang dengan kriteria yang telah diuraikan, maka terpilih sampel sebanyak 35 perusahaan dalam penelitian ini. Kemudian dari 35 perusahaan yang terpilih yang digunakan sampel ialah data saham dari 35 perusahan pada periode 10 hari sebelum dan periode 10 hari setelah peristiwa kenaikan BI Rate. Metode pengumpulan data dalam penelitian ini adalah metode dokumentasi publikasi yaitu dengan cara mengambil data publikasi dari Bursa Efek Indonesia (BEI). Metode analisis data yang digunakan adalah dengan teknik analisis uji beda yang bertujuan untuk mengamati perbedaan hasil rata-rata kelompok sampel yaitu dari pergerakan harga saham pada pasar modal sebelum dan setelah adanya informasi mengenai pengumuman kenaikan BI Rate tertanggal 12 November 2013. Analisis data yang digunakan adalah model analisis paired sample t-test.

Variabel yang digunakan untuk menganalisis reaksi pasar di proksikan dengan abnormal return dan trading volume activity. Menurut Tandelilin (2010:609) Abnormal return saham atau return tak normal $\left(\mathrm{RTN}_{\mathrm{i}}\right)$ merupakan selisih (positif atau negatif) dari return aktual terhadap return normal. Return normal merupakan return ekspektasian (return yang diharapkan oleh investor). Untuk menghitung abnormal return dapat menggunakan rumus sebagai berikut:

$$
\mathrm{AR}_{\mathrm{it}}=\mathrm{R}_{\mathrm{it}}-\mathrm{R}_{\mathrm{mt}}
$$

Keterangan:

$\mathrm{AR}_{\mathrm{it}}=$ Abnormal return sekuritas ke-i pada periode peristiwa ket

$\mathrm{R}_{\mathrm{it}}=$ Return sesungguhnya yang terjadi untuk sekuritas ke-i pada periode peristiwa ke- $\mathrm{t}$ $\mathrm{R}_{\mathrm{mt}}=$ Return ekpektasi pasar untuk periode peristiwa ke-t.

Dalam penelitian ini menggunakan model disesuaikan pasar (marketadjusted model) untuk menghitung return ekspektasi (expected return) yang menganggap bahwa penduga terbaik untuk mengestimasi return suatu sekuritas adalah return indeks pasar pada saat tersebut. Dengan menggunakan model ini, maka tidak perlu menggunakan periode estimasi, karena return sekuritas yang diestimasi adalah sama dengan return 
indeks pasar (Jogiyanto, 2013:612). Berikut adalah rumus menghitung Market Adjusted Model:

$$
R m t=\frac{\left(\mathrm{IHSG}_{\mathrm{t}}-\mathrm{IHSG}_{\mathrm{t}-1}\right)}{\mathrm{IHSG}_{\mathrm{t}-1}}
$$

Keterangan:

Rmt = Return pasar

IHSGt $=$ Indeks harga saham gabungan penutupan pada peride $\mathrm{t}$

IHSGt $_{-1}=$ Indeks harga saham gabungan penutupan pada periode sebelumnya

Untuk menghitung return sesungguhnya yang terjadi maka digunakan selisih harga sekarang relatif terhadap harga sebelumnya yang diformulasikan sebagai berikut (Jogiyanto, 2010: 236):

$$
\text { Rit }=\frac{\text { Pit }- \text { Pit }_{-1}}{\text { Pit }-1}
$$

Keterangan:

Rit $=$ Return realisasi sekuritas I pada hari ke-t

Pit $=$ Harga saham sekarang relatif

Pit $=$ Harga saham hari sebelumnya

Trading volume activity (TVA) atau sering disebut sebagai aktifitas volume perdagangan adalah jumlah saham yang diperdagangkan pada hari tertentu. TVA adalah alat yang digunakan untuk melihat tingkat likuiditas saham dan juga untuk melihat apakah informasi pengumuman kenaikan BI Rate dinilai sebagai sesuatu yang informatif bagi investor. Trading Volume Activity (TVA) dapat dihitung dengan rumus sebagai berikut:

$$
T V A=\frac{\sum \text { saham yang diperdagangkan }}{\sum \text { saham yang beredar }}
$$

\section{HASIL DAN PEMBAHASAN}

Hipotesis pertama dalam penelitian ini adalah terdapat perbedaan rata-rata abnormal return sebelum dan setetelah peristiwa pengumuman kenaikan BI Rate. Setelah mengamati persebaran data dengan statisik deskriptif, selanjutnya dilakukan pengujian terhadap hipotesis pertama dengan menggunakan uji beda untuk sampel berhubungan (Paired sample t-test) dengan tingkat signifikansi sebesar 5\% atau 0,05. Berikut ini hasil pengolahan data rata-rata abnormal return saham LQ45 sebelum dan setelah peristiwa pengumuman kenaikan BI Rate dengan menggunakan paired sample ttest.

Penggunaan Abnormal return dalam penelitian ini digunakan untuk mengukur reaksi pasar modal yang dilihat dari tingakat keuntungan (Rokhman dkk, 2009:663). Apabila pengumuman kenaikan BI Rate memiliki kandungan informasi maka pasar 
akan bereaksi terhadap pengumuman tersebut yang ditunjukkan dengan adanya perubahan harga saham.

Tabel 1

Uji Beda Rata-rata Abnormal Return 10 hari sebelum dan 10 hari setelah

Peristiwa Pengumuman Kenaikan BI Rate

Paired Samples Test

\begin{tabular}{|c|c|c|c|}
\hline & \multirow{2}{*}{$\begin{array}{c}\text { Pair 1 } \\
\text { AAR_Sebelum - } \\
\text { AAR_Setelah }\end{array}$} \\
\hline & & & \\
\hline $\begin{array}{l}\text { Paired } \\
\text { Differences }\end{array}$ & $\begin{array}{l}\text { Mean } \\
\text { Std. Deviation } \\
\text { Std. Error Mean } \\
95 \% \text { Confidence } \\
\text { Interval of the } \\
\text { Difference }\end{array}$ & $\begin{array}{l}\text { Lower } \\
\text { Upper }\end{array}$ & $\begin{array}{r}-.00103 \\
.00502 \\
.00159 \\
-.00462 \\
.00256\end{array}$ \\
\hline $\begin{array}{l}\text { T } \\
\text { Df } \\
\text { Sig. (2-tailed) }\end{array}$ & & & $\begin{array}{r}.649 \\
9 \\
.533 \\
\end{array}$ \\
\hline
\end{tabular}

Tabel 1 menunjukkan bahwa rata-rata abnormal return selama 10 hari sebelum pengumuman kenaikan BI Rate (t-10 sampai t-1) dan 10 hari setelah pengumuman kenaikan BI Rate ( $\mathrm{t}+1$ sampai $\mathrm{t}-1)$ diperoleh sebesar $-0,00103 \%$ atau terjadi reaksi pasar yang negatif. Namun demikian, hasil pengujian perbedaan rata-rata abnormal return sebelum dan setelah peristiwa secara statistik diperoleh nilai $\mathrm{t}=-0,649$ dengan signifikansi sebesar 0,533 atau berada di atas $0,05(5 \%)$. Hal ini berarti, tidak terdapat perbedaan yang signifikan secara statistik antara rata-rata abnormal return sebelum dan setelah peristiwa pengumuman kenaikan BI Rate. Dengan demikian, hipotesis pertama dalam penelitian ini ditolak.

Investor tidak melihat bahwa kenaikan BI rate akan mempengaruhi investasi mereka di pasar saham. Kenaikan BI rate tidak memberikan dampak bagi perdagangan di bursa dan merupakan "no news" karena investor tidak menganggap bahwa kenaikan BI rate akan memberikan dampak yang negatif bagi perusahaan. Dari pengujian terhadap hipotesis satu tidak ditemukan adanya perbedaan yang signifikan antara ratarata abnormal return sebelum dan setelah peristiwa pengumuman kenaikan BI Rate, sehingga hipotesis yang menyatakan terdapat reaksi pasar yang ditunjukkan dengan perbedaan rata-rata abnormal return pada periode sebelum dan setelah pengumuman kenaikan BI Rate pada Indeks LQ45 tidak terbukti

Hasil Penelitian yang diperoleh dapat dijadikan acuan bahwa ternyata informasi kenaikan BI Rate tidak memberikan signal negatif. Investor yang ingin berinvestasi tidak hanya menggunakan informasi kebijakan pemerintah dalam menentukan langkah investasinya (Linawati, 2009). Tidak adanya reaksi pasar modal yang ditunjukkan dengan tidak adanya perbedaan antara abnormal return sebelum dan setelah peristiwa kenaikan BI Rate menunjukkan bahwa kondisi pasar modal Indonesia berjalan dengan normal walaupun ada kebijakan baru yang dikeluarkan oleh pemerintah. Dengan kenaikan BI Rate maka risiko gagal bayar akan semakin meningkat dan hal itu akan 
membahayakan dana yang telah ditanamkan oleh investor. Investor dapat mempertimbangkan informasi kebijakan pemerintah dan memperhitungkan risiko yang akan terjadi pada perusahaan setelah adanya kebijakan tersebut sehingga disamping mendapatkan return yang tinggi, dana yang telah mereka tanamkan di pasar modal tidak akan terkena dampak negatif dari adanya kebijakan pemerintah seperti kenaikan BI Rate (Linawati,2009).

Hipotesis kedua dalam penelitian ini adalah terdapat reaksi pasar yang ditunjukkan dengan perbedaan trading volume activity (TVA) pada periode sebelum dan setelah pengumuman kenaikan BI Rate pada Indeks LQ45. Trading volume activity digunakan sebagai indicator dalam melihat reaksi pasar modal yang diukur dari tingkat likuiditas (Rokhman dkk,2009:663). Perdagangan saham yang aktif dapat meningkatkan volume perdagangan dan menujukkan bahwa saham tersebut digemari oleh investor. Dengan cepatnya saham diperdagangakan, maka akan memberi petunjuk bahwa saham tersebut semakin likuid.

Berdasarkan hasil pengujian pada rata-rata trading volume activity untuk perusahaan anggota LQ45 pada tabel diperoleh bahwa t hitung sebesar 4,002 dengan nilai sigifikansi sebesar 0,003 . Nilai signifikansi 0.003 lebih kecil dibanding 0.05 sehingga $\mathrm{H} 2$ diterima. Hal ini berarti terdapat perbedaan yang signifikan pada rata-rata trading volume activity antara sebelum dan sesudah peristiwa pengumuman kenaikan BI Rate. Dengan diterimanya hipotesis kedua $(\mathrm{H} 2)$ berarti informasi baru berupa kenaikan $\mathrm{BI}$ rate memiliki kandungan informasi yang mampu membuat pasar bereaksi dengan melihat aktivitas perdagangan saham yang terjadi akan mempengaruhi investasi mereka di pasar saham.

Tabel 2

Uji Beda Rata-rata Trading Volume Activity (ATVA) 10 hari sebelum dan 10 hari setelah Pengumuman Kenaikan BI Rate

Paired Samples Test

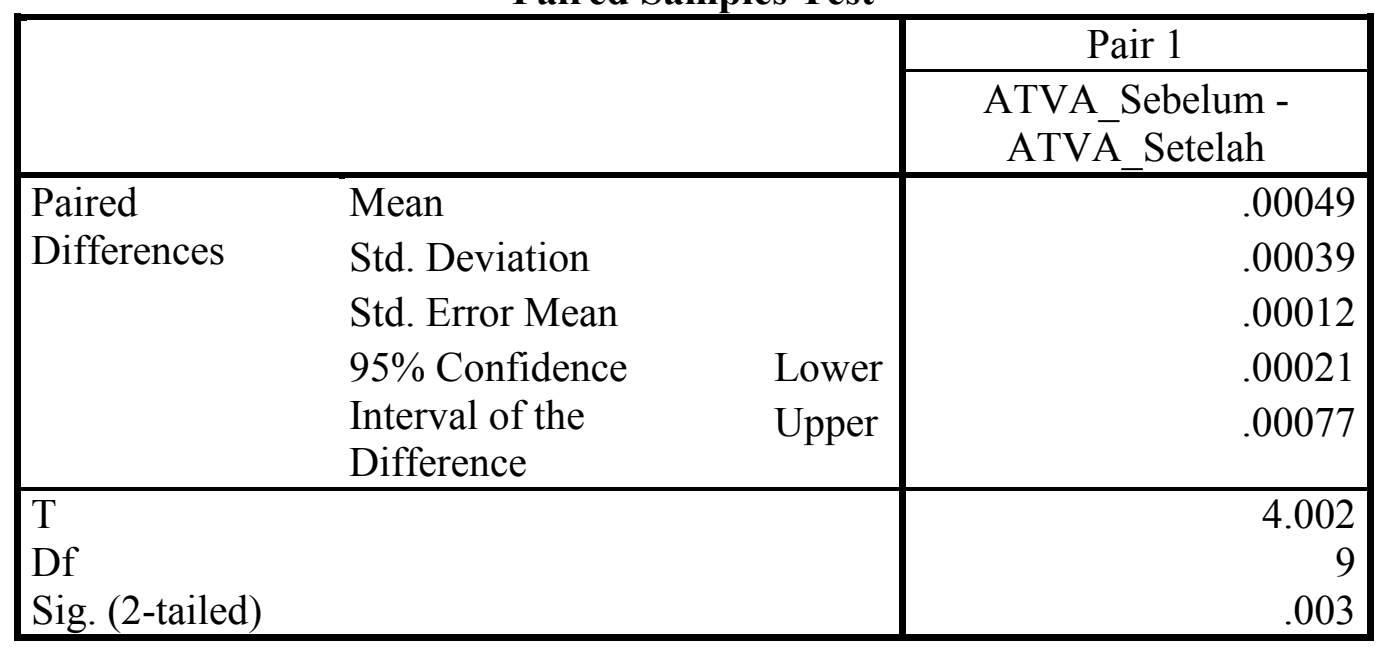


Tabel 2 menunjukkan bahwa rata-rata trading volume activity selama periode pengamatan sebelum dan setelah pengumuman kenaikan BI Rate diperoleh sebesar 0,00049 atau terjadi perdagangan saham sebesar $0,49 \%$ dari seluruh saham yang ada. Hasil pengujian perbedaan rata-rata TVA secara statistik diperoleh $\mathrm{t}=4,002$ dengan signifikansi sebesar 0,003 atau berada dibawah 0,05. Hal ini berarti bahwa, terjadi perbedaan yang signifikan rata-rata trading volume activity (TVA) saham LQ45 sebelum dan setelah pengumuman kenaikan BI Rate.

Dari hasil penelitian tersebut, menunjukkan bahwa sebelum dan setelah pengumuman kenaikan BI Rate terjadi reaksi pasar atas perdagangan saham yang ditunjukkan dengan rata-tara trading volume activity sehingga hipotesis kedua dapat diterima. Peristiwa kenaikan BI Rate memberikan sinyal tentang adanya informasi buruk terhadap aktivitas bursa atau pergerakan harga saham yang menurun. Adanya reaksi pasar modal yang ditunjukkan dengan adanya perbedaan antara trading volume activity sebelum dan setelah peristiwa kenaikan BI Rate menunjukkan bahwa kondisi pasar modal Indonesia tidak berjalan dengan normal, adanya perubahan aktivitas pelaku pasar berupa supply dan demand atas perdagangan saham yang terjadi di Bursa Efek Indonesia (BEI).

\section{KESIMPULAN DAN SARAN} berikut:

Berdasarkan hasil penelitian dan pembahasan, maka dapat disimpulkan sebagai

1. Tidak terdapat perbedaan yang signifikan antara average abnormal return sebelum dan setelah peristiwa pengumuman kenaikan BI Rate. Dengan demikian, pengumuman kenaikan BI rate tidak menggerakkan abnormal return di pasar.

2. Terdapat perbedaan yang signifikan antara average trading volume activity sebelum dan setelah pengumuman kenaikan BI Rate. Dengan demikian menunjukkan bahwa pengumuman kenaikan BI Rate mempengaruhi keputusan investor dalam melakukan transaksi di pasar modal, sehingga menimbulkan perbedaan rata-rata TVA.

Berdasarkan kesimpulan dan keterbatasan penelitian, maka terdapat beberapa saran yang dihasilkan dari penelitian ini, yaitu:

1. Bagi perusahaan, penelitian ini menyarankan agar mengamati perubahan harga saham, sehingga apabila terkena dampak kebijakan pemerintah, perusahaan dapat mengambil keputusan untuk mengantisipasi hal tersebut.

2. Bagi investor, penelitian ini menyarankan hendaknya mempertimbangkan dampak dari informasi kebijakan pemerintah dan kondisi makro yang akan terjadi pada perusahaan setelah adanya kebijakan tersebut sebelum mengambil keputusan investasi.

3. Bagi penelitian selanjutnya, penelitian ini menyarankan beberapa hal, yaitu:

a. Dalam menentukan nilai return ekspektasian (expected return) dapat menggunakan model estimasi berupa mean adjusted model atau market model yang melakunan perhitungan return realisasi pada periode estimasi (periode sebelum periode pengamatan) terlebih dahulu (Jogiyanto, 2013: 610).

b. Melakukan pengelompokan sampel berdasarkan struktur modal perusahaan, sehingga diharapkapkan memberikan hasil yang berbeda atas reaksi yang terjadi akbibat adanya pengumuman kenaikan BI Rate (Linawati, 2009: 3).

c. Menambah variabel lain selain abnormal return dan trading volume activity untuk menggambarkan reaksi pada pasar modal, seperti variabel return, dan bidask spread saham (Rockhman, 2009: 663). 


\section{DAFTAR REFERENSI}

Bernanke, B. \& Kuttner, K. (2005). What Explains The Sthock Market's Reaction to Federal Reserve Policy? The Journal of Finance, Vol LX, No.3.

Birru, J. \& Figlewski, S. (2010). The Impact of the Federal Reserve's Interest Rate Target Announcement on Stock Price: A Closer Look at How the Market Impounds New Information. Script. New York University Stren School of Business.

Fama, F.E. (1997). Market Efficiency, Long-Term Return, and Behavioral Finance. Journal of Finance Economics, Vol.49, hal: 283-306.

Ferdinand, Augusty. (2011). Metode Penelitian Manajemen. Semarang: Badan Penerbit Universitas Diponegoro.

Iswardono. (1999). Suku Bunga Diturunkan Investasi Akan Meningkat? Jurnal Ekonomi dan Bisnis Indonesia, Vol 14.

Jogiyanto, H. (2013). Teori Portofolio dan Analisis Investasi. Yogyakarta: BPFE.

Lantara, I.W.N. (2004). Perubahan Tingkat Suku Bunga dan Kinerja Pasar Modal Indonesia. Jurnal Ekonomi dan Bisnis Indonesia, Vol 19.

Linawati, D. (2009). Dampak Pengumuman Kenaikan BI Rate Tanggal 07 Oktober 2008 Terhadap Abnormal Return dan Trading Volume Activity. Tesis. Semarang: Fakultas Ekonomi UNDIP.

Rokhman, M.T.N., Afandy, D.P., \& Kiptiyah, S.M. (......). Analisis Return, Abnormal Return, Aktivitas Volume Perdagangan dan Bid-Ask Spread Saham di Seputar Pengumuman Stock Split. Wacana, Vol.12, No. 4, Hal: 662-677.

Tandelilin, E. (2010). Portofolio dan Investasi Teori dan Aplikasi. Yogyakarta: Kanisius.

Tjahjono, H.K. (2004). Pengaruh Kurs dan Suku Bunga Terhadap Indeks Harga Saham LQ 45. Jurnal Ekonomi \& Studi Pembangunan, Vol 5.

Ulumuddin, A.S. (2010). Pengaruh Pengumuman Penuruan BI Rate Terhadap Return dan Risiko Saham Sektor Perbankan Indonesia Juni 2009. Skripsi. Malang: Fakultas Ekonomi UIN MMI.

http://www.bi.go.id/id/moneter/bi-rate/data/Default.aspx (25 November 2013).

http://www.idx.co.id/id-id/beranda/informasipasar/saham/ringkasansaham.aspx

(7 Februari 2014).

http://www.ksei.co.id/announcements/ksei_announcement (6 Februari 2014). 